Original Article

\title{
PHYSICAL COMORBIDITY AND FUNCTIONAL DISABILITY AMONGST MENTALLY ILL INMATES IN NIGERIAN PRISON
}

\author{
Armiya'u Y.A, ${ }^{1 *}$ Lubuola I.B, ${ }^{1}$ Tungchama F.P. ${ }^{2}$ \\ ${ }^{1}$ Department of Psychiatry, Jos University Teaching Hospital and ${ }^{2}$ University of Jos/Jos University Teaching Hospital, Nigeria \\ *Corresponding Author: Armiya'u A.Y, Department of Psychiatry, Jos University Teaching Hospital. Plateau state Nigeria. Tel: \\ +2348035899338 .
}

Published: November $23^{\text {rd }} 2018$

\begin{abstract}
Comorbidity is the presence of more than one disorder/condition at the same time, and it is common among those with mental illness. Prisoners with multiple disorders are more disabled and consume more health resources than those with only one disorder. This study aimed at providing prevalence of physical comorbidity among inmates with mental illness and the relationship between physical comorbidity and functional disability among this group of inmates. The study was part of a comprehensive descriptive cross-sectional study carried out among 608 prisoners awaiting trial and convicted in Jos maximum security prison, Plateau state. Four sets of questionnaires were used namely Sociodemograhic Questionnaire (for demographic variable), General Health Questionnaire (GHQ-28) for screening the prisoners for a mental health problem, Composite International Diagnostic Interview (CIDI) which is a structured clinical interview for diagnosing mental health disorders while Physical and functional disabilities were evaluated using the PULSE profile Questionnaire. Out of 608 participants 347 (57.1\%) had mental disorders of which 63 (18.2\%) had physical comorbidity, with infectious diseases being the commonest physical challenge. Functional disability (level of functioning) was significantly associated with comorbidity cutting across all physical disorders found in the study. The study found high physical comorbidity among mentally ill inmates in the prison studied.
\end{abstract}

Keywords: Comorbid physical illness, functional disability, prevalence, pulses profile, prison inmates

\section{Introduction}

Nigerian Prison population is enormous as reported by the International Centre for Prison Studies with a total prison inmate of 71,522 including pre-trial detainees/remand prisoners as at 2018. ${ }^{1}$ Considering non-commensurate infrastructural facilities in correctional centers of low income countries including Nigeria, compared to the geometrically increasing population of prisoners, it is less surprising that these group of people are particularly disadvantaged with respect to the basic needs of life made available to them and required health services. Consequently, they are highly vulnerable to communicable and noncommunicable diseases such as HIV/AIDS, tuberculosis, Hepatitis, hypertension, diabetes mellitus among others. ${ }^{2}$ The illnesses can impact on their activities of daily living which will further worsen their deplorable health conditions and overall quality of life. The complex and dynamic relationship between mental and physical illness was highlighted in the Chief Medical Officer's 2013 annual report, with a focus on public mental health priorities. ${ }^{1}$ It was reported that individuals with mental illness tend to experience worse physical health than those without mental illness. Psychiatric disorder in patients with chronic medical conditions is associated with worse quality of life because such patients comply poorly with medication ${ }^{3}$. Several studies in developed and developing countries have assessed prevalence of chronic illness in the prison population viz physical and mental illnesses. For example, Wilper et $\mathrm{al}^{4}$ in a United State of America based study, found prevalence of chronic illness of $38.5 \%$ among the inmates in a Federal Correctional centre and $69.1 \%$ of the sample population were on psychotropics after admission. In a similar study conducted in USA, chronic illness was found higher among the prison population compared to the community population. ${ }^{5}$ 
Singleton et al reported physical illness to be more common among people who have drug problems, especially those in dependency states. ${ }^{6}$ They reported that musculoskeletal problems were the most common co-morbid physical illness among male prisoners in England and Wales followed by respiratory problems. While these studies examined the chronic medical illness in this population, the scope is beyond looking at comorbidity of mental and physical illnesses and more importantly, how it impacts on their functional ability or activities of daily living. Furthermore, studies conducted in India, ${ }^{7}$ Zambia, $^{8}$ Ghana $^{9}$ and Nigeria ${ }^{10-13}$ largely assessed the prevalence of mental illness in the prison population. Unlike the studies conducted in the developed countries, less attention was paid to comorbid physical illness in the mentally ill patients. Armiya'u et $a l,{ }^{14}$ in a Nigerian study attempted to bridge this gap by examining co-morbid physical illness among prisoners with mental illness in the prison population. They found $57 \%$ of the study sample to have Psychiatric disorders among whom $18 \%$ had physical comorbidity. However, the study like others conducted elsewhere in Nigeria did not examine the clinical implication of this comorbidity on their areas of functioning. The observations from the aforementioned studies created gaps in knowledge regarding physical comorbidity with mental illness and its implication on functional disability. It is important to assess the functional disability in this prison population whose burden of mental illness has been further compounded by physical illness. Thus given an evidenced based knowledge on how they are particularly predisposed to disability, by virtue of coexistence of the two diagnoses which obviously require different human and material resources for satisfactory management. This further suggests mental health services to prisoners should adopt a holistic approach embracing both mental and physical health when and where available.

We hypothesized that functional disability would not be significantly higher among prisoner with mental illness and physical comorbidity compared to those without. In the light of the foregoing, this study intends to complement previous studies by examining the functional disability among prisoners with mental illness with and without comorbid physical illness in a North Central Nigerian maximum Prison.

\section{Materials and Methods}

The study is part of a comprehensive cross-sectional study carried out among 608 males (as only 5 female inmates were in prison at the time of the study) both convicted and awaiting trial inmates in Jos maximum security prison. The duration of the study was 24 weeks, January to June, 2013. Inclusion criteria include male inmates who consent to be studied. Exclusion criteria include male inmates who refuse to give consent and those who are too ill to participate.

The study was carried out at the Jos prison, Jos, Plateau State Nigeria. The prison was established in 1940 with an inmate capacity of 900 ; but now has a capacity of 1150 prisoners though without any additional infrastructure. It is a maximum security prison. Its area of coverage includes Adamawa, Bauchi, Benue, Borno, Plateau, Taraba, and Yobe states. These states constitute, approximately $30 \%$ of the surface area of Nigeria and have an estimated population of $24,380,042 .{ }^{15}$ Convicts serving life sentences or condemned for execution are usually homicide offenders and armed robbers who are isolated from other prisoners under condition of maximum security.

Convicted homicide offenders are found in the main condemned convicts ward (MCC), other convicts are found in A ward, the B ward is occupied by armed robbery suspects, $\mathrm{D}$ and $\mathrm{J}$ wards occupied by condemned criminals and life sentence inmates, $\mathrm{L}$ and $\mathrm{M}$ wards are occupied by awaiting trial inmates, $\mathrm{N}$ ward is occupied by life sentence inmates who are elderly and tuberculosis ward which contain convicts suffering from tuberculosis. There is a female convict's ward which serves all categories of female offenders. The prison has a prison social worker, who liaises with the social welfare services of the prison regarding the welfare of convicts. An occupational rehabilitation service exists, and provides opportunity for convicts to participate in carpentry, metal works and other varieties of craft work (convicted homicide offenders and other life-sentenced prisoners are excluded from participating) because this group of inmates are not likely to leave the prison. An adult education programme is available to all categories of prisoners from secondary level of education.

A church and a mosque are provided for religious worship by convicts. Each ward is partitioned into cubicles measuring 10 feet by 10 feet, to accommodate four inmates; this in consequence is associated with congestion as they are occupied by 10-15 inmates, which is often considered very uncomfortable by the inmates. Bedding in most cases consists of cardboard or mats covered with blankets (often infested with lice and bedbug). The Jos prison health service includes a health clinic manned by five qualified nurses with $30,23,19,18,12$ years working experience respectively but none of them has post 
basic nursing training in psychiatry, clinical psychologist and intern psychologist, public and community health staff, and a prison clinic with 12 beds.

The data was collected in two stages as follows: In the first stage, each consecutive participant was administrated the socio-demographic questionnaire (for data such as age, gender, educational status etc.) alongside the 28-item General Health Questionnaire (GHQ-28). The GHQ-28 is a self-administered screening instrument which was given to all the participants. It was designed to cover four identifiable areas of distress: depression, anxiety, social impairment and hypochondriasis. The GHQ questionnaires have been used in over 38 countries including Nigeria and over 50 validity studies have been published. It has been demonstrated to have high sensitivity and specificity. ${ }^{12,14}$

In the second stage, participants with GHQ-28 score of four (4) and above were administered the Composite International Diagnostic Interview (CIDI). CIDI is a comprehensive, fully standardized interview that can be used to assess mental disorder and provide diagnosis according to the definition and criteria of the tenth revision of the International Classification of Diseases ICD 10 and the fourth edition of the Diagnostic and Statistical Manual of mental disorder (DSM IV). ${ }^{16-17}$ The instrument has been validated, and used by researchers in different countries, e.g. in Nigeria. $^{14,18}$ All inmates with physical comorbidity had laboratory investigations carried out on them with their consent. This includes urinalysis, full blood count and fasting blood sugar. A positive test is when fasting blood sugar, full blood count or urinalysis are deranged either above or below normal values, while negative test is when the result is within the normal values of conducted investigations.

History, detailed physical examination and available baseline investigations were carried out on inmates. Pulses profile was used to evaluate physical and functional disabilities for participants with evidence of physical comorbidity. Pulses profile is an instrument designed to evaluate any physical or functional disability in the activities of the daily living of a chronically ill patient or elderly patient or an institutionalized population. ${ }^{19}$ It indicates impairment in terms of physical abnormalities. The components of the acronym PULSES are as follows $\mathrm{P}=$ physical condition, $\mathrm{U}=$ upper limb function, $\mathrm{L}=$ lower limb function, $\mathrm{S}=$ sensory component (speech, vision, hearing), $\mathrm{E}=$ excretory function, $\mathrm{S}=$ mental and emotional status. Granger et $a l,{ }^{20}$ reported a test retest reliability of 0.87 and inter-rater reliability exceeding
0.95. Each of the six components of the acronym PULSES received equal scores ranging from 1 to 4 (1 $=$ no gross abnormality considering the age of the patient, $4=$ severe abnormality). Summation of the six components which results in a range of scores from 6 , indicating no functional disability as a result of the physical illness considering the age of the patient, to 24 which indicates severe physical or functional disability.

\section{Reference Standard Score}

Scores above 6 but below 12 indicate mild disability; score above 12 but below 16 reflect moderate disability and the scores above 16 represent severe disability. ${ }^{20}$ Most of the validity studies were carried out in the United States. The validity profile of the Pulses Profile was calculated using Java Stat 2-way contingency table analysis. ${ }^{20}$ Agboola used the pulses instrument in a study he did in Calabar Prison, first time use of the instrument in this environment ${ }^{18}$. Agboola did a pilot study that involved 10 inmates who were not included in his final analysis. His study was done to assess the test retest reliability of the instrument. The Cronbach's alpha correction obtained in Agboola's pilot study was 0.82 which was comparable to 0.87 obtained by Granger et al. ${ }^{20}$ Physical illnesses were classified under the broad categories of ICD 10 in this study. Assessment was carried out by the researchers who are all consultant psychiatrist.

\section{Ethical Consideration}

Permission was granted by the Prison Authority of Jos. Ethical approval was obtained and granted by the Ethical Committee of Jos University Teaching Hospital. All participants signed or thumb printed for informed consent before the study.

\section{Statistical Analysis}

The Statistical Package for Social Sciences (SPSS) version 20.0 software package was used to analyze the data. Simple descriptive analysis was use to summarize sociodemographic variable using frequency count and percentage. The chi-square test was used to investigate the relationship between mental disorder and comorbid physical illness and statistical significance was set at $P<0.05$. 


\section{Results}

Out of the 608 studied participants 347 (57\%) had psychiatric morbidity (Table 2). The commonest diagnosis was Substance Use Disorder 169(27.8\%), Depressive disorder accounted for 107 (17.6\%), Generalized anxiety disorder was found among $41(6.7 \%)$, panic disorder in 21(3.5\%), psychosis $4(0.7 \%)$, intermittent explosive disorder and mania both accounted for 2(0.3\%) each (Table 3). Of the 347 participants with psychiatric morbidity $63(18.2 \%)$ had a comorbid physical illness (Table 4 ). The prevalence of comorbid physical illness was found in 63 (18\%) of the studied participants. Infectious diseases (A00A99) were the most common 13(3.74\%) physical comorbidity among participants. Diseases of the musculoskeletal system (M00-M99) ranked second with $12(3.45 \%)$. One participant had disease in two systems (Circulatory and Respiratory) (Table 4). Statistically significant association was found across all physical diseases and functioning in all inmates with physical comorbidity (mental illness and physical illness) (Table 5-7). On available baseline investigations carried out on 63(18.2\%) participants with physical comorbidity 8 had positive result on fasting blood sugar (FBS), 17 on urinalysis and 22 for full blood count (FBC) (Figure 1).

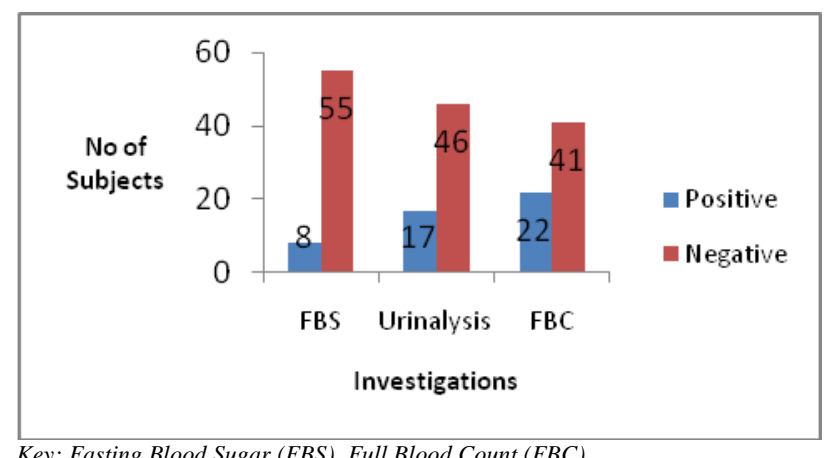

Fasting Blood Sugar (FBS), Full Blood Count (FBC)

Figure 1: Results of Laboratory Investigations of the participants

Table 1: General Health Questionnaire (GHQ) - 28 Score Profile

\begin{tabular}{lcc}
\hline GHQ -28 score & Frequency & Percentage \\
\hline $0-3$ & 261 & 42.9 \\
$4-7$ & 182 & 29.9 \\
$8-11$ & 102 & 16.8 \\
$>11$ & 63 & 10.4 \\
\hline Total & $\mathbf{6 0 8}$ & $\mathbf{1 0 0}$ \\
\hline
\end{tabular}

Table 2: Psychiatric Morbidity of Participants by GHQ-28

\begin{tabular}{lcc}
\hline GHQ & Frequency & Percentage \\
\hline Cases & 347 & 57.1 \\
No cases & 261 & 42.9 \\
\hline Total & $\mathbf{6 0 8}$ & $\mathbf{1 0 0}$ \\
\hline
\end{tabular}

Table 3: Composite International Diagnostic Interview (CIDI) Diagnosis

\begin{tabular}{lcc}
\hline $\begin{array}{l}\mathrm{N}=608 \\
\text { Type }\end{array}$ & $\begin{array}{c}\text { Frequency } \\
\text { Depression (D) }\end{array}$ & Percentage \\
\hline $\begin{array}{l}\text { Generalized Anxiety } \\
\text { Disorder (G) }\end{array}$ & 107 & 17.6 \\
Panic Disorder (P) & 21 & 6.7 \\
Psychosis (PS) & 4 & 3.5 \\
$\begin{array}{l}\text { Substance use } \\
\text { Disorder (SU) }\end{array}$ & 169 & 0.7 \\
Mania (M) & 2 & 27.8 \\
$\begin{array}{l}\text { Intermittent Explosive } \\
\text { Disorder (IED) }\end{array}$ & 2 & 0.3 \\
$\begin{array}{l}\text { Depressive/substance use } \\
\text { Disorder }\end{array}$ & 1 & 0.3 \\
No psychiatric Disorder & 261 & 0.2 \\
\hline
\end{tabular}

Table 4: Co-Morbid Physical Illness among the Participants

\begin{tabular}{lcc}
\hline $\begin{array}{l}\mathrm{N}=347 \\
\text { Type of physical illness }\end{array}$ & $\begin{array}{r}(18.2 \%) \\
\text { Frequency }\end{array}$ & Percentage \\
\hline $\begin{array}{l}\text { Diseases of musculoskeletal } \\
\text { system (M00 - M99) }\end{array}$ & 12 & 3.45 \\
$\begin{array}{l}\text { Diseases of the eye } \\
\text { (H00 - H95) }\end{array}$ & 5 & 1.44 \\
$\begin{array}{l}\text { Diseases of ear and mastoid } \\
\text { process (H60 - H95) }\end{array}$ & 9 & 2.59 \\
$\begin{array}{l}\text { Diseases of circulatory system } \\
\text { (I00 - I99) }\end{array}$ & 10 & 2.88 \\
$\begin{array}{l}\text { Diseases of respiratory system } \\
\text { (J00 - J99) }\end{array}$ & 8 & 2.30 \\
$\begin{array}{l}\text { Diseases of endocrine system (E) } \\
\text { Infectious diseases (A) }\end{array}$ & 4 & 1.15 \\
$\begin{array}{l}\text { Diseases of gastrointestinal system (K) } \\
\text { Disease of respiratory/circulatory systems }\end{array}$ & 1 & 3.74 \\
No co-morbid physical illness & 13 & 0.3 \\
\hline
\end{tabular}

Table 5: Relationship between Co-Morbid Physical Illnesses and Functional Disability Profile of Subjects

\begin{tabular}{lrrrr}
\hline & \multicolumn{3}{c}{$\begin{array}{c}\text { Co-morbid physical illness } \\
\text { N= 608 } \\
\text { Total }\end{array}$} & Statistics \\
& Present & Absent & & \\
\hline FDP Frequency (\%) & \multicolumn{3}{c}{ Frequency (\%) } \\
Disease of the eye & $7(100.0)$ & - & $7(100)$ & $* \mathrm{P}=0.000$ \\
$\begin{array}{l}\text { Disease of the ear } \\
\text { And mastoid process }\end{array}$ & $8(89.0)$ & $1(11.0)$ & $9(100)$ & \\
Absent & $48(8.0)$ & $544(92.0)$ & $592(100)$ \\
\hline
\end{tabular}


There was a significant association between co-morbid physical illnesses and the functional disability profile for sensory function of studied participants. Participants with co morbid disease of the eye/disease of the ear and mastoid process had mild functional disability compared to participants without co-morbidity.

Key

FDP: Function Disability Profile

Table 6: Relationship between Co-Morbid Physical Illnesses and Functional Disability Profile among Subjects

\begin{tabular}{lcccc}
\hline & \multicolumn{4}{c}{ Co-morbid physical illness } \\
& Present & Absent & Total & Statistics \\
& & & & \\
\hline FDP Frequency (\%) & & Frequency (\%) & \\
$\begin{array}{l}\text { Musculoskeletal } \\
\text { system }\end{array}$ & $9(100.0)$ & - & & \\
& & & & \\
& & & & \\
Absent & $54(9.0)$ & $545(91.0)$ & $599(100)$ &
\end{tabular}

*Fisher's exact test: $\mathrm{P}$ value is statistically significant.

A significant relationship was found between co-morbid physical illnesses and functional Disability profile for lower extremities function of the inmates. This implies that inmates with co morbid diseases of the musculoskeletal system had mild functional disability compared to those inmates without co morbidity.

Key : Functional Disability Profile: Functional Disability Profile for Lower

Extremities

Table 7: Relationship between Co-Morbid Physical Illnesses and Functional Disability Profile among Subjects

\begin{tabular}{|c|c|c|c|c|}
\hline & \multicolumn{3}{|c|}{$\begin{array}{l}\text { Co-morbid physical illness } \\
\qquad N=608\end{array}$} & \multirow[b]{2}{*}{ Statistics } \\
\hline & Present & Absent & Total & \\
\hline FDP Frequency (\%) & \multicolumn{2}{|c|}{ Frequency $(\%)$} & & \\
\hline Respiratory system & $9(100.0)$ & - & $9(100)$ & $* \mathrm{P}=0.000$ \\
\hline Cardiovascular system & $5(63.0)$ & $3(37.0)$ & $8(100)$ & \\
\hline Infectious diseases & $10(56.0)$ & $8(44.0)$ & $18(100)$ & \\
\hline Endocrine system & $4(80.0)$ & $1(40.0)$ & $5(100)$ & \\
\hline Gastrointestinal system & $1(100.0)$ & - & $1(100)$ & \\
\hline Absent & $34(6.0)$ & $533(94.0)$ & $567(100)$ & \\
\hline
\end{tabular}

*Fisher's exact test: P value is statistically significant.

Statistical significance was found between co-morbid physical illnesses and functional disability profile for physical conditions among participants studied. This implies that co morbid physical conditions are related to some form of functional disability $9(100 \%)$ in participants with respiratory system diseases, $4(80 \%)$ with endocrine system diseases and $1(100 \%)$ with gastrointestinal diseases) had mild functional disability compared to $34(6.0 \%)$ without co morbidity.

Key: PPP: Functional Disability Profile for Physical Condition.

\section{Discussion}

The physical illnesses were grouped under the broad category of ICD 10. Infectious diseases were the most prevalent co-morbid physical illness in the study which was found in $(3.74 \%)$ of the participants. Most of the infectious diseases were as a result of HIV infection (9 out of 13) that is $69 \%$ of participants with infectious disease had HIV. This disease was possibly contracted from risky life style, such as unprotected sexual exposure, and sharing of needles even though no one in the study reported intravenous substance use but it could have been concealed by the participants. Disease of the musculoskeletal system ranked second (3.45\%), which was found among inmates who were mostly older and had a longer stay in the prison. Some of them are getting older and having problems with their limbs such as arthritis, while others had gunshot injuries prior to imprisonment which were not properly treated, resulting in mal-union of fractured bones. Disease of circulatory system ranked third $(2.88 \%)$. Some of the inmates with this problem are receiving anti-hypertensive medication at the prison clinic. Diseases of the respiratory system was found in $8(2.8 \%)$ of the participants. Majority of the participants are living in congested cells with several other cell mates who might be having one form of infection or the other, which will subsequently be transmitted to some other cell mates.

Prevalence of co-morbid physical illness was found in $(18 \%)$ of the studied participants, which was a little higher than what was reported in a Nigerian study $(15 \%)$ conducted in the southern part of the country. ${ }^{12}$ The relatively higher rate of comorbid physical illness found in our study compared to reported prevalence in the Nigerian study may be related to methodological differences. For instance, they assessed 100 inmates and no structured instrument was employed in the determination of physical comorbidity. In addition, they conducted this study in a medium security prison where degree of offence is less severe as against what operates in maximum security prison where our study was conducted. It is a known fact that inmates in maximum security prison may get more involved in substance use and reckless activities with attendant physical comorbidity. Authors reported that diseases of the gastro-intestinal system (peptic ulcer/ inguinal hernia) were the most common physical illness, followed by disease of the eye. ${ }^{12}$ Another study from Nigeria reported a higher prevalence rate of $(39.6 \%)$ among his studied subjects. ${ }^{18}$ Considerable lower prevalence of physical illness found in our study vis a vis the higher rates recorded in southern part of Nigeria is also presumed to occur due to variability in factors such as the standard of available medical facilities and age of the participants. They reported in their findings that only one medical officer attends to inmates in a poorly equipped health facility. However, the medical facility in Jos maximum security prison has a full complement of Medical officers, Nurses and visiting Specialists with a greater propensity to 
promptly identify and treat diagnosed physical illness, thus, a lower prevalence of physical comorbidity. Authors reported disease of musculoskeletal system as first which was followed by disease of the eye. ${ }^{18}$ Furthermore, the observation in our study that infectious diseases is the most diagnosed physical illness is expected considering higher prevalence of HIV in Plateau state and North Central in general. In support of this fact, a larger percentage of the participants in this study reside in North Central Nigeria. On the other hand, observation of higher percentage of musculoskeletal problems in Calabar study may not be unconnected to the age distribution of the participants who were much younger with a greater likelihood to engage in life threatening criminality that has potential for musculoskeletal injuries. Psychiatric disorder in patients with chronic medical conditions is associated with worse quality of life. $^{21}$ Severe conditions are likely to require psychiatric treatment and may carry a risk for suicide. ${ }^{21}$ Moderately severe disorder may also require treatment and if it persists, may delay recovery from the physical illness. Psychiatric disorder may be a cause for poor compliance with medical treatment and excessive or inappropriate use of medical services. The possibility that a psychiatric disorder may interfere with recovery from physical illness was suggested by the findings of Querido ${ }^{22}$ where he found that medical outcome seven months later, was significantly worse in patients who had more psychiatric symptoms at the time of the original illness. ${ }^{22}$

Functional disability negatively affects the quality of life of inmates, and is determined by several factors which include physical illness, health conditions, among others. ${ }^{23}$ There was a significant association between co-morbid physical illnesses and functional disability as measured by the PULSES profile. The co-morbid physical illnesses reported earlier in this study were associated with some form of disabilities which includes mobility and vision and these will obviously impact on activities of daily living in the affected inmates. The complications that often arise from HIV infection will further perpetuate the morbidity of the physical illness and worsen their level of participation in activities that will improve their health and overall quality of life. Studies have found relationship between chronic disease and functional disability, therefore early intervention will be necessary to reduce the negative impact of this conditions. ${ }^{24}$ Measures to be taken should focus on contributing to the natural history of the disease in a favourable way, and delay the disease evolution and complication, which might be reflected on the maintenance and improvement of functional capacity of the inmate. ${ }^{2}$

\section{Conclusion}

These results suggest high rate of physical comorbidity among participants with mental illness in the prison studied, and a statistically significant relationship between comorbid physical illness and functional ability using Pulsus Profile as a guide in the study.

\section{Recommendation}

Authors recommend that all prisoners with mental illness should be screened for physical comorbidity, documented and followed up; with the aim of reducing the suffering to the affected prisoners and consequent deterioration with poor compliance to psychiatric medication.

\section{Conflict of Interests}

The Authors declare no conflict of interests.

\section{Funding}

The study was entirely funded by Authors

\section{References}

1. World Prison Brief Data. Overview of Nigerian prisons. Institute for Criminal Policy Research, Birkbeck University of London, on: http:// www. Prisonstudies.org/country/Nigeria. Accessed on 10/06/2018

2. Fazel S, Danesh J. Serious mental disorder in 23000 prisoners: A systematic review of 62 surveys. Lancet. 2002; 359:545-550.

3. Stewart AL, Greenfield S, Wells K. Functional status and wellbeing of patients with chronic condition. Journal of American Medical Association. 1989;262:907-913.

4. Wilper AP, Woolhandler S, Boyd JW, Lasser $\mathrm{KE}$, et al. The health and health care of US Prisoners: results of a nationwide survey. 2009;99(4):666-672.

5. Binswanger IA, Krueger PM, Steiner JF. Prevalence of chronic medical conditions among jail and Prison inmates in the USA compared with the general population. Journal of Epidemiology and Community Health. 2009;63(11):912-919.

6. Singleton N, Meltzer H, Gatward R. Psychiatric morbidity among prisoners in England and Wales (office for National statistics). London stationery office. 1998 
7. Goyal SK, Singh P, Gorgi PD, Goyal S, Garg A. Psychiatric Morbidity in Prisoners. Indian Journal of Psychiatry. 2011;53(3):253-257.

8. Nseluke MT, Siziya S. Prevalence and Sociodemographic Correlates for Mental illness Among Inmates at Lusaka Central Prison Zambia. Medical Journal of Zambia.2011;38(2):1-5

9. Ibrahim A, Esene RK, Aikins M, O'Keefee AM, Mc Kay M. Assessment of Mental distress among Prison inmates in Ghana's Correctional system: a cross-sectional study using Kessler Psychological Distress Scale. International Journal of Mental Health System. 2015;9:17

10. Aishatu YA, Bwatyum AG, Kurkat M., Suwa, GG. Co-Morbid Physical Illness among Depressed Prisoners in a Nigerian Prison Population. J Forensic Sci \& Criminal Inves, 2017;4(2):555638.DOI:10.19080/JFSCI.20 17.04.555638.

11. Fatoye FO, Fatoye GK, Oyebanji AO, Ogunro AS, Psychological Characteristics as Correlates of emotional burden in incarcerated Offenders in Nigeria. East African Medical Journal.2006;83(10)545-552.

12. Agbahowe SA, Ohaeri JU, Ogunlesi AO, Osahon R. Prevalence of Psychiatric morbidity among convicted Inmates in a Nigerian Prison Community. East African Medical Journal 1998;75(1):19-26.

13. Nwaopara U, Stanley P. Prevalence of Depression in Port Harcourt Prison. J Psychiatry, 2015;18:340.

14. Armiya'u AY, Audu MD, Obembe A. Adole O, Umar MU. A study of psychiatric morbidity and comorbid physical illness among convicted and awaiting trial inmates in Jos prison. Journal of Forensic and Legal Medicine. 2013;20(8):10481051.

15. National Population Commission. National Ministry of Internal Affairs. Census. 2006

16. World Health Organization. International Classification of Mental Health disorder (ICD10). WHO Geneva. 1992-93

17. American Psychiatric Association. Diagnostic and Statistical Manual of Mental Disorder, $4^{\text {th }}$ Edition. 1994

18. Agboola A. A study of psychiatric and comorbid physical illness among inmates in Calabar prison. An unpublished fellowship thesis submitted to the West African College of Physicians. 2006
19. MoskowitzE, McCann CB. PULSES Profile. $1957 ; 44-49$

20. Granger CV, Albrecht GL, Hamilton, BB. Outcome of comprehensive medical rehabilitation: measurement of PULSES profile and the Barthel index. Arch Physical Medicine and Rehabilitation. 1979;(60):145-154.

21. Butler T., Allnutts., Yang, B. Mentally ill prisoners in Australia have poor physical health. International Journal of Prison Health. 2007;3(2),99-110.

22. Querido A. Forecast and follow up: an investigation into the clinical, social and mental factors determining the result of hospital treatment. British Journal of Preventive and Social Medicine.1959;13,334-339

23. Pereira MAL, Rodrigues, MC. Perfil da capacidadefuncionalemidososresidentes no condomínio Vila vidaemJataí-GO. Rev Bras AtivFísSaúde.2017;12(1):2733.Accessedfrom: $\underline{\mathrm{ht}}$ tps://periodicos.ufpel.edu.br/ojs2/index.php/RBA FS/article/view/803/812

24. Gonçalves SX., Brito GEG., Oliveira EA, Carvalho DB, et al. Capacidade funcional de idososadscritos à Estratégia Saúde da Família no município de João Pessoa - PB. Rev Bras Ciênc Saúde. 2011;15(3):287-94. Accessed from: http://periodicos.ufpb.br/ojs/index.php/rbcs /article/view/10566

25. Brito KQD, Menezes TN, Olinda RA. Functional disability: health conditions and physical activity practice in older adults. Rev. Bras. Enferm. 2016;69(5):773-80. 